\title{
Nonsteroidal Anti-Inflammatory Agents in the Therapy for Experimental Pneumococcal Meningitis
}

\author{
Elaine Tuomanen, Bruno Hengstler, Roland Rich, \\ Michael A. Bray, Oto Zak, \\ and Alexander Tomasz
}

\author{
From the Laboratory of Microbiology, the Rockefeller \\ University, New York, New York; and the Research \\ Departments, Pharmaceuticals Division, \\ Ciba-Geigy Limited, Basel, Switzerland
}

\begin{abstract}
An increased inflammatory mass in the subarachnoid space during bacterial meningitis may correlate with a poor outcome of disease. Using a rabbit model of pneumococcal meningitis, we sought to reduce this inflammatory process. The ability of the pneumococcal cell wall to cause death and to generate leukocytosis and abnormal chemistry in cerebrospinal fluid was prevented when animals were treated with inhibitors of the cyclooxygenase pathway of arachidonate metabolism. Bacterial lysis by ampicillin led to release of cell wall that caused a significant, transient increase in meningeal inflammation. This inflammatory burst was also prevented by administering cyclooxygenase inhibitors concurrently with the antibiotic.
\end{abstract}

The morbidity and mortality associated with pneumococcal meningitis is directly proportional to the amount of inflammation in the subarachnoid space [1]. Much of the inflammatory response to the pneumococcus arises from the triggering of local host defenses by the pneumococcal cell surface, particularly the cell wall, which underlies the capsule [2, 3]. Both the complement and the arachidonic acid pathways generate chemotactic factors in response to the bacterial cell wall [4]. Because the target of the $\beta$-lactam family of antibiotics is the bacterial cell wall, current modes of chemotherapy enhance the release of cell wall products during bacterial lysis and killing. Many of these products are highly inflammatory when instilled into the CSF space [3]. Although effective bacterial killing can be achieved by current antibiotic therapy, inflammation may actually be transiently enhanced as the bacteria lyse. We explored this possibility by using a rabbit model of pneumococcal meningitis. Because cell wall-induced inflammation involves the generation of chemotactic factors from the arachidonic acid pathway, these studies were designed to determine if modulation of antibiotic-induced enhancement of inflammation

Received for publication 4 August 1986, and in revised form 10 October 1986.

This work was supported in part by the Irma T. Hirschl Research Award to E. T., by a matching grant from the Infectious Diseases Society of America, and by grants AI-16794 and AI23459 from the National Institute of Allergy and Infectious Diseases.

Please address requests for reprints to Dr. Elaine Tuomanen, The Rockefeller University, Box 152, 1230 York Avenue, New York, New York 10021. could be achieved by administering nonsteroidal, anti-inflammatory agents that block the generation of some arachidonate metabolites. This treatment regimen may improve the prognosis for patients with meningitis; morbidity has remained stable at $30 \%$ despite achievement of excellent bactericidal activity in CSF.

\section{Materials and Methods}

Streptococcus pneumoniae strain $\mathrm{S}_{\mathrm{III}}$ is a type III clinical strain from Dr. M. Sande (San Francisco, Calif). Bacteria were grown in casein hydrolysate medium at $37 \mathrm{C}$ [2], and midlogarithmic-phase organisms were harvested, washed in saline, and inoculated into the cisterna magna of rabbits at a concentration of $10^{3} \mathrm{cfu}$ in $0.2 \mathrm{ml}$ of pyrogen-free saline (Ciba-Geigy, Basel, Switzerland). Bacterial concentrations were titrated for cfu on trypticase-soy agar containing 5\% sheep's blood.

Cell walls from unencapsulated S. pneumoniae strain R6 were prepared by extraction of disrupted cells with boiling in SDS, digestion with nucleases and proteases, repeat SDS extraction, and extensive washing [4]. Lyophilized cell walls were suspended in pyrogen-free saline (Ciba-Geigy) at a concentration of $30 \mu \mathrm{g}$ in $0.2 \mathrm{ml}$, were sonicated briefly, and were instilled into the cisterna magna of rabbits. This concentration corresponds to $\sim 10^{8}$ whole cell equivalents and is known to cause a brisk inflammatory response in CSF within $5 \mathrm{hr}$ of challenge [2].

The rabbit model of meningitis was similar to Dacey and Sande's [5], as described [2,3]. Male chinchilla rabbits weighing $2 \mathrm{~kg}$ (Thome Farm, Biebarach 
der Riss, FRG) were tested in groups of four animals each. Ampicillin $(50 \mathrm{mg} / \mathrm{kg})$ was administered iv at $18 \mathrm{hr}$ postinfection by bolus infusion in saline into an ear vein for $10 \mathrm{~min}$. Table 1 shows the dosing schedule for animals receiving either steroids or nonsteroidal anti-inflammatory agents. All medications were obtained from Ciba-Geigy.

The density of leukocytes in CSF was determined in serial samples by using a Coulter counter, and the concentration of protein in CSF was determined by using the Lowry microdilution method [2]. To determine the concentration of arachidonic acid-pathway metabolites, we centrifuged samples of CSF $(200 \mu \mathrm{l})$ at $10,000 \mathrm{~g}$ for $5 \mathrm{~min}$ to remove leukocytes, and the supernatant fluids were frozen at $-70 \mathrm{C}$ for up to three months before analysis. The samples were thawed, precipitated in 5 volumes of methanol, centrifuged at 5,000 $\mathrm{g}$ for $30 \mathrm{~min}$ at $4 \mathrm{C}$, and dried under argon evaporation. Samples were suspended in PBS and assayed in duplicate. The presence of leukotriene $\mathrm{B}_{4}\left(\mathrm{LTB}_{4}\right)$ was determined both directly by bioassay of methanol-extracted supernatants and indirectly after high-pressure liquid chromatography (HPLC) and bioassay of the fraction containing LTB $_{4}$, as determined from a synthetic standard; the bioassay used aggregation of rat peritoneal neutrophils (sensitive to the picogram level) [6]. The concentration of prostaglandin $\mathrm{E}_{2}\left(\mathrm{PGE}_{2}\right)$ in methanolextracted samples was determined by standard RIA (sensitive to the picogram level) [7].

Statistical analysis of a single parameter between groups was performed by the two-tailed Student's $t$ test.
Results

Effect of inhibitors of the arachidonic acid metabolic pathway on inflammation. Intracisternal challenge with $10^{8}$ cell equivalents of pneumococcal cell wall $(30 \mu \mathrm{g})$ rapidly induced the influx of PMNLs and protein into the CSF. With a single dose of cell walls, the CSF abnormalities were transient, with the peak occurring at $7 \mathrm{hr}$ postchallenge. Table $1 \mathrm{sum}$ marizes the effect of inhibition of the arachidonic acid pathway on the degree of inflammation after an intracisternal challenge with $10^{8}$ whole cell equivalents of pneumococcal cell walls. In all cases, protein concentrations closely paralleled the number of leukocytes. The lipoxygenase inhibitor nordihydroguaiaretic acid did not significantly decrease the CSF inflammatory response to cell walls. In contrast, the most-effective inhibitors of this response were methylprednisolone and the cyclooxygenase inhibitor oxindanac (CGP 6258), which decreased the number of leukocytes by $>90 \%$. The cyclooxygenase inhibitors diclofenac sodium and indomethacin also reduced inflammation, but not as effectively as methylprednisolone and oxindanac. The effects of oxindanac and indomethacin were dose-dependent, as shown in figure 1 . As the doses of drug were decreased, the mean number of leukocytes present in CSF increased toward control values.

Four rabbits were challenged with repeated intracisternal doses of cell walls $(200 \mu \mathrm{g})$ at $0,5,8$, and $24 \mathrm{hr}$. These repeated doses led to a greater and more-sustained CSF leukocytosis than did single doses $($ mean $\pm S D): 5,984 \pm 1,566,19,155 \pm 3,875$,

Table 1. Effect of cyclooxygenase and lipooxygenase inhibitors on CSF leukocytosis in rabbits after intracisternal injection of $30 \mu \mathrm{g}$ of pneumococcal cell walls.

\begin{tabular}{lccccc} 
& & & \multicolumn{3}{c}{ CSF leukocytosis after } \\
\cline { 4 - 6 } Compound & Dose $(\mathrm{mg} / \mathrm{kg})$, route & Time of administration* & $5 \mathrm{hr}$ & $7 \mathrm{hr}$ & $24 \mathrm{hr}$ \\
\hline Control & - & - & $677 \pm 34$ & $1,545 \pm 90$ & $870 \pm 92$ \\
Methylprednisolone & $30 \mathrm{im}$ & -1 & $50 \pm 20$ & $198 \pm 30 \ddagger$ & $54 \pm 20$ \\
Diclofenac sodium & $5 \mathrm{iv}$ & $-1,+2$ & $110 \pm 40$ & $433 \pm 210 \ddagger$ & $1,183 \pm 150$ \\
Indomethacin & $5 \mathrm{po} \S$ & $-1,+2,+5$ & $155 \pm 60$ & $300 \pm 50 \ddagger$ & $320 \pm 50$ \\
Nordihydroguaiaretic acid & $5 \mathrm{po}$ & $-1,+2,+5$ & $1,093 \pm 500$ & $870 \pm 240$ \\
Oxindanac & $5 \mathrm{po}$ & $-1,+2,+5$ & $118 \pm 57$ & $59 \pm 14 \ddagger$ & $500 \pm 325$ \\
\hline
\end{tabular}

NOTE. po $=$ perorally.

* In reference to time, in hours, of cell wall challenge dose.

$\dagger$ Mean of leukocytes $/ \mu \mathrm{l}$ of CSF $\pm \mathrm{SD}$; value at $0 \mathrm{hr}, 28 \pm 14$ cells $/ \mu \mathrm{l}$.

$\ddagger$ Significant differences, $P<0.01$ compared with control at $7 \mathrm{hr}$.

$\$$ Administered by bolus injection through feeding tube. 


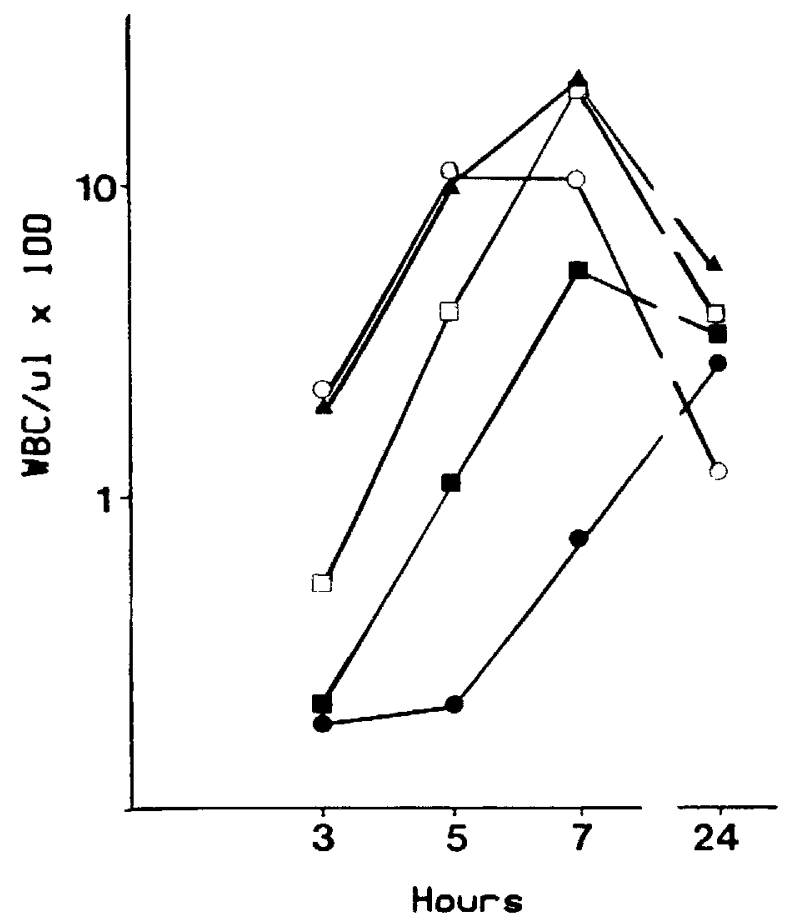

Figure 1. Inhibition of cell wall-induced leukocytosis in CSF by inhibitors of arachidonate metabolism. Groups of four rabbits were challenged intracisternally with $30 \mu \mathrm{g}$ of pneumococcal cell wall at time 0 . The leukocyte density appearing in CSF over $24 \mathrm{hr}$ was determined in groups receiving the following treatments at $-1,2$, and $5 \mathrm{hr}$ : no drug (A), oxindanac po at $1.5 \mathrm{mg} / \mathrm{kg}(0)$ or $5 \mathrm{mg} / \mathrm{kg}(\Theta)$, and indomethacin po at $1.5 \mathrm{mg} / \mathrm{kg}(\square)$ or $5 \mathrm{mg} / \mathrm{kg}(\square)$. Values for oxindanac and indomethacin at $5 \mathrm{mg} / \mathrm{kg}$ at 3 , 5 , and $7 \mathrm{hr}$ were statistically different from controls $(P$ $<.01)$.

and $12,540 \pm 1,819$ cells $/ \mu 1$ in CSF samples taken just before the wall challenges at 5,8 , and $24 \mathrm{hr}$, respectively. Rabbits receiving repeated doses of cell walls exhibited opisthotonus and paralysis, and two of four animals died after the fourth dose.

When repeated intracisternal doses of cell walls were adminstered to rabbits that were pretreated orally with oxindanac $1 \mathrm{hr}$ before cell wall challenge, the outcome was quite different. Leukocytosis was less marked at 5, 8, and 24 hours: $5,330 \pm 1,771$, $9,755 \pm 1,734,5,515 \pm 3,523$ cells $/ \mu \mathrm{l}$, respectively $(P<.05$ at 8 and $24 \mathrm{hr})$. Meningeal signs were again seen in the animals, but none of the animals experienced paralysis or died. Thus, oxindanac decreased both the leukocyte number in CSF and the incidence of severe meningeal signs such as paralysis and death.

Table 2 compares the CSF concentration of $\mathrm{PGE}_{2}$ and the number of leukocytes appearing in CSF after challenge with cell walls or live pneumococci. Control preparations of whole pneumococci, cell walls, or diclofenac sodium did not interfere with the assay when tested directly (i.e., $\mathrm{PGE}_{2}$ values, $<1$ ng). Five hours after intracisternal challenge with cell walls or living organisms, large increases in leukocyte density (40-100-fold) and $\mathrm{PGE}_{2}$ concentration (20-60-fold) occurred in CSF. In contrast, both the leukocyte number and the $\mathrm{PGE}_{2}$ concentration remained low when the cyclooxygenase inhibitor diclofenac sodium was administered in conjunction with cell walls. No CSF samples tested showed any detectable LTB $_{4}$ bioactivity either in methanolextracted supernatants or after HPLC purification. Thus, the activity of inhibitors of the cyclooxygenase pathway in decreasing the magnitude of inflammation due to pneumococcal cell walls appeared to correlate with low concentrations of $\mathrm{PGE}_{2}$ in CSF.

Effect of bacterial lysis on CSF inflammation. Figure 2 demonstrates the effect of bacterial lysis caused by ampicillin on the density of leukocytes in CSF. At $30 \mathrm{~min}$ postinfusion, the peak ampicillin concentration was reached $(0.5 \mu \mathrm{g} / \mathrm{ml})$ and exceeded the MIC for strain $\mathrm{S}_{\text {III }}(0.01 \mu \mathrm{g} / \mathrm{ml})$ by 50 -fold. Bacterial killing ensued (decrease in $\mathrm{cfu}$ from $10^{5.8}$ $\mathrm{cfu} / \mathrm{ml}$ before ampicillin to $10^{2} \mathrm{cfu} / \mathrm{ml} 5 \mathrm{hr}$ after treatment with ampicillin). Bacterial lysis was documented by the appearance of debris in CSF samples examined by light microscopy. As lysis progressed, an abrupt influx of PMNLs occurred, which

Table 2. Correlation between CSF leukocytosis and concentration of $\mathrm{PGE}_{2}$ in CSF of rabbits challenged with pneumococci or cell walls.

\begin{tabular}{|c|c|c|}
\hline \multirow[b]{2}{*}{ Treatment conditions } & \multicolumn{2}{|c|}{$\begin{array}{c}\text { Mean values in CSF at } \\
7 \mathrm{hr} \text { postchallenge* }\end{array}$} \\
\hline & $\begin{array}{c}\text { Leukocytosis } \\
\text { (cells } / \mu 1 \\
\text { of CSF) }\end{array}$ & $\begin{array}{c}\mathrm{PGE}_{2} \\
\text { (ng/ml of } \mathrm{CSF} \text { ) }\end{array}$ \\
\hline Control (saline alone) & 40 & 0.3 \\
\hline $10^{7.5}$ Live pneumococci & 4,570 & 18.6 \\
\hline Purified cell wall $(30 \mu \mathrm{g})$ & 1,545 & 6.1 \\
\hline $\begin{array}{l}\text { Diclofenac sodium (iv) plus } \\
30 \mu \mathrm{g} \text { of cell wall (ic) } \dagger\end{array}$ & 433 & $0.4 \ddagger$ \\
\hline
\end{tabular}

* Arithmetic mean of two challenges; SD $\pm<200$ for leukocyte number and $\pm<0.5$ for $\mathrm{PGE}_{2}$ concentration.

$\dagger$ ic = intracisternally.

$\ddagger$ Significantly different from group treated with cell wall alone, $P<.01$. 


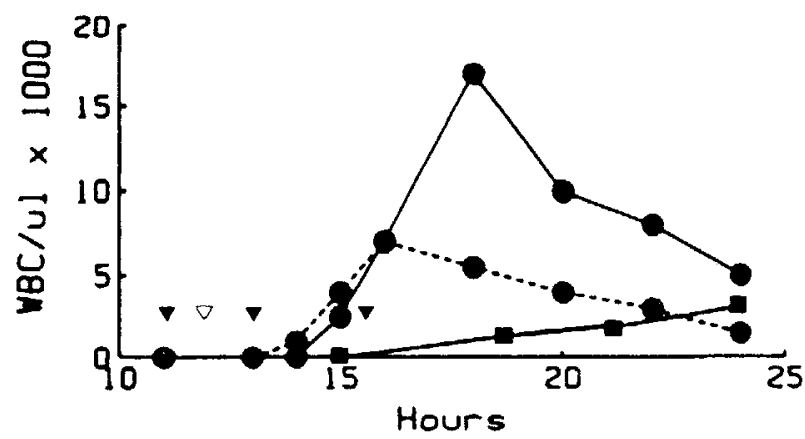

Figure 2. Effect of cyclooxygenase inhibitor on CSF leukocytosis after challenge with pneumococcal strain SIII. Groups of five rabbits were challenged at time 0 with $10^{3}$ pneumococci. The density of leukocytes in CSF was studied over $\mathbf{2 4} \mathrm{hr}$ in groups treated as follows: no treatment (E); ampicillin ( $\bullet$ ), $50 \mathrm{mg} / \mathrm{kg}$ iv at the time indicated by the open triangle; or ampicillin plus oxindanac ( - - - $), 5 \mathrm{mg} / \mathrm{kg}$ po at the time indicated by the closed triangles.

was absent in control animals not receiving ampicillin (in which bacterial multiplication continued). Thus, lysis and killing of pneumococci in the CSF space was accompanied by a transient burst of increased inflammation.

To determine if the anti-inflammatory effects of cyclooxygenase inhibitors would modulate the inflammation associated with bacterial lysis in vivo, we used oxindanac and ampicillin to treat animals with established pneumococcal meningitis. As shown in figure 2, the number of leukocytes appearing in CSF after a dose of ampicillin was significantly lower in the animals that also received oxindanac. Oxindanac did not alter the concentration of ampicillin in the CSF (data not shown). Importantly, effective bacterial killing occurred in oxindanac-treated animals despite the lower density of CSF leukocytes; $a \geqslant 3 \log$ killing occurred by $2 \mathrm{hr}$ postampicillin treatment in both the control and the oxindanac-treated animals.

\section{Discussion}

The mortality from pneumococcal meningitis is directly correlated with the amount of meningeal inflammation [1]. Two parameters used to quantitate the inflammatory response are the density of CSF leukocytes and the protein concentration, both of which are increased during natural infection. Our previous studies indicated that these abnormalities in CSF cytochemistry in experimental meningitis can be generated by the interaction of host defenses with the pneumococcal cell wall [2-4]. The current results indicate that mortality is also associated with the persistent presence of bacterial cell wall in the subarachnoid space. Bacterial lysis in vivo and in vitro involves the explosive release of cell wall degradation products into the surrounding environment. The results reported here show that ampicillin-induced killing of pneumococci in vivo, which entails such lysis, is associated with a transient enhancement of the inflammatory response in the CSF space. This is consistent with the fact that the major products of pneumococcal autolysis are components of the cell wall that are known to be highly inflammatory in this meningitis model $[2,3]$.

Because enhancement of inflammation associated with bacteriolysis may contribute to the poor outcome of meningitis despite effective bacterial sterilization, it was important to determine if the host response to this transient inflammatory stimulus associated with chemotherapy could be modulated. The present studies indicate that it is possible to reduce the inflammatory response in the CSF space by inhibiting noncomplement-mediated host defenses. Several inhibitors of the cylcooxygenase pathway of arachidonic acid metabolism proved to be highly effective in reducing the influx of leukocytes and the elevation of protein concentration associated with intracisternal inoculation with cell walls. Methylprednisolone and oxindanac were particularly effective, whereas indomethacin and diclofenac sodium were moderately effective. In contrast, inhibitors of primarily the lipoxygenase pathway were ineffective in preventing cell wall-induced inflammation. When tested against the natural infection, administering cyclooxygenase inhibitors in conjunction with $\beta$-lactam antibiotics also markedly reduced inflammation associated with release of inflammatory bacterial products during bacterial lysis by ampicillin.

Surprisingly, the arachidonic acid pathway that appears to play a significant role in generating inflammation in the subarachnoid space of the rabbit is not the lipooxygenase pathway, which generates the powerful chemotaxin leukotriene $B_{4}$, but rather, the cyclooxygenase pathway. This conclusion is based on several lines of evidence. First, direct measurement of arachidonic acid pathway metabolites suggested a positive correlation between the concentration of $\mathrm{PGE}_{2}$ and the number of leukocytes that appeared 
in CSF in response to either living pneumococci or purified pneumococcal cell walls. Secondly, inhibitors of the cyclooxygenase pathway reduced both $\mathrm{PGE}_{2}$ concentrations and CSF inflammation in response to pneumococcal challenge. Prostaglandins of the $\mathrm{E}$ series are known to induce fever in response to endogenous pyrogen and to increase in concentration in response to challenge of rabbits with Escherichia coli or Shigella endotoxin [8, 9]. $\mathrm{PGE}_{2}$ are also known to have direct effects on PMNLs, including inhibition of chemotaxis in response to immune complexes and inhibition of degranulation of leukocytes activated by the chemotactic peptide formylmethionyl-leucyl-phenylalanine $[10,11]$. These direct effects would not, however, explain the correlation of high concentrations of $\mathrm{PGE}_{2}$ with increased leukocytosis in CSF. Thus, our results do not distinguish whether $\mathrm{PGE}_{2}$ causes a previously undescribed enhancement of leukocyte chemotaxis in this particular site of infection or whether other cyclooxygenase metabolites are the direct chemotaxins, and the $\mathrm{PGE}_{2}$ response is correlated but secondary.

The approach we have taken to identify modes of therapy that would decrease the currently stable morbidity and mortality of meningitis has rested on the thesis that decreased inflammation is a new goal to be achieved in an era of chemotherapy in which bacterial killing is easily attained. Leukocytes in inflammatory exudates can most certainly contribute directly to local tissue injury, particularly if host cell membranes are coated with inflammatory bacterial components (i.e., cell walls and lipid-linked cell wall congeners). Cell walls can generate leukocytosis by activating several host defenses $[4,12]$, and from the present study, these components can even induce death. The most-significant finding of this study is that inhibiting the activity of one arm of the CSF defense system, the cyclooxygenase pathway, appears to reduce both the total CSF inflammatory mass and to improve survival. Preliminary studies have confirmed and extended this association between cyclooxygenase inhibitors and enhanced survival in other instances of experimental meningeal inflammation (O. Z., unpublished observations).

To further improve the outcome of bacterial meningitis, we must identify the pathological lesions associated with morbidity and mortality. Leukocyteinduced damage is almost certainly not the only source of destructive lesions. For instance, from the studies of Tauber et al. [13, 14], CSF pressure is known to correlate with bacterial density and with the concentration of cell walls in the CSF space. Brain edema does not appear to show this correlation. Yet, neither of these pathological lesions nor even simple abnormalities in CSF chemistry are directly dependent on leukocytes because all occur in neutropenic animals [13-15]. Furthermore, our recent studies indicate that death can be caused by intracisternal inoculation of cell walls in both normal and neutropenic animals (E. T., unpublished observations). Thus, the processes that generate leukocytosis may also generate, in parallel, tissue damage independent of leukocytes. In this regard, the ability of the arachidonic acid cascade to generate mediators capable of altering vascular permeability, platelet function, etc. in addition to chemotaxins, may be important. Thus, it may be the multiplicity of effects of inhibitors of the arachidonic acid pathway that is critical to linking decreased leukocytosis, decreased tissue damage, and enhanced prognosis. The combination of effects of individual inhibitors varies, and the relative proportion of these effects with the greatest benefit for outcome of disease remains to be determined. Cyclooxygenase inhibitors such as diclofenac sodium and oxindanac, however, appear to be excellent candidates for improving outcome of therapy when used in conjunction with $\beta$ lactam antibiotics to achieve bacterial killing during pneumococcal meningitis.

\section{References}

1. McAllister CK, O'Donoghue JM, Beaty HN. Experimental pneumococcal meningitis. II. Characterization and quantitation of the inflammatory process. J Infect Dis 1975; 132: $355-60$

2. Tuomanen E, Tomasz A, Hengstler B, Zak $O$. The relative role of bacterial cell wall and capsule in the induction of inflammation in pneumococcal meningitis. J Infect Dis 1985;151:535-40

3. Tuomanen E, Liu H, Hengstler B, Zak O, Tomasz A. The induction of meningeal inflammation by components of the pneumococcal cell wall. J Infect Dis 1985;151:859-68

4. Tuomanen E, Hengstler B, Zak O, Tomasz A. The role of complement in inflammation during experimental pneumococcal meningitis. Microbial Pathogenesis 1986;1:15-32

5. Dacey RG, Sande MA. Effect of probenecid on cerebrospinal fluid concentrations of penicillin and cephalosporin derivatives. Antimicrob Agents Chemother 1974;6:437-41

6. Bray MA. Retinoids are potent inhibitors of the generation of rat leukocyte leukotriene $B_{4}$-like activity in vitro. Eur J Pharmacol 1984;98:61-7

7. White HL, Glassman AT. A simple radiochemical assay for prostaglandin synthetase. Prostaglandins 1974;7:123-9

8. Bernheim HA, Gilbert TM, Stitt JT. Prostaglandin E levels in third ventricular cerebrospinal fluid of rabbits during 
fever and changes in body temperature. J Physiol 1980; 301:69-78

9. Philipp-Dormston WK, Siegert R. Prostaglandins of the E and $F$ series in rabbit cerebrospinal fluid during fever induced by Newcastle Disease virus, $E$. Coli-endotoxin, or endogenous pyrogen. Med Microbiol Immunol 1974; 159:279-84

10. Fantone JC, Marasco WA, Elgas LJ, Ward PA. Anti-inflammatory effects of prostaglandin $\mathrm{E}_{1}$ : in vivo modulation of the formyl peptide chemotactic receptor on the rat neutrophil. J Immunol 1983;130:1495-7

11. Kaplan HB, Edelson HS, Korchak HM, Given WP, Abramson S, Weissmann G. Effects of non-steroidal antiinflammatory agents on human neutrophil functions in vitro and in vivo. Biochem Pharmacol 1984;33:371-8

12. Ernst JD, Hartiala KT, Goldstein IM, Sande MA. Complement (C5)-derived chemotactic activity accounts for ac- cumulation of polymorphonuclear leukocytes in cerebrospinal fluid of rabbits with pneumococal meningitis. Infect Immun 1984;46:81-6

13. Täuber MG, Khayam-Bashi H, Sande MA. Effects of ampicillin and corticosteroids on brain water content, cerebrospinal fluid pressure, and cerebrospinal fluid lactate levels in experimental pneumococal menigitis. J Infect Dis 1985;151:528-34

14. Täuber MG, Tuomanen $E$, Zak $O$, Sande MA. Increased intracranial pressure induced by pneumococcal cell walls [abstract no. 683]. In: Program and abstracts of the 25th Interscience Conference on Antimicrobial Agents and Chemotherapy. Washington, DC: American Society for Microbiology, 1985

15. Ernst JD, Decazes JM, Sande MA. Experimental pneumococcal meningitis: role of leukocytes in pathogenesis. Infect Immun 1983;41:275-9 